\title{
Ações de prevenção de contágio do novo coronavírus em um centro integrado de inclusão e reabilitação: relato de experiência
}

\author{
Actions for the prevention of new coronavirus contacts in an integrated inclusion and \\ rehabilitation center: experience report
}

\begin{abstract}
Acciones para la prevención de nuevos contactos de coronavirus en un centro integrado de inclusión y rehabilitación: informe de experiencia
\end{abstract}

Leisson Domingues Pinheiro ${ }^{1 *}$, Ricardo Gomes Junior ${ }^{1}$, José Luz Batista Neto ${ }^{1}$, Paola Alejandra Valenzuela Reyes ${ }^{1}$, Nayara Cavalcante Fernandes ${ }^{1}$, Claudete Ferreira Quintino ${ }^{1}$, Fabrícia Dias Maciel ${ }^{1}$.

\section{RESUMO}

Objetivo: Relatar a experiência da implantação de ações coordenadas em um Centro Integrado de Inclusão e Reabilitação para prevenção ao novo Coronavírus. Relato de experiência: Este estudo constitui um relato de experiência de caráter descritivo da implantação de ações coordenadas para prevenção do novo coronavírus seguindo as recomendações sanitárias federal, estadual e municipal. Entre as ações implantadas do comitê de crise, backup de atividades assistenciais, protocolos clínicos, material de comunicação, acompanhamento de psicológicos para colaboradores e realização de teste. Considerações finais: $O$ centro adotou todas as medidas orientadas pelos órgãos sanitários, implantando de forma organizada as ações e multiplicando informações entre os colaboradores, usuários e familiares. É importante implantar uma política de testagem em massa. Possivelmente teríamos um mapa epidemiológico mais confiável para análise, colocando em pauta também as discussões socioeconômicas que são bastante distintas no Brasil. $O$ momento é reunir todas as opiniões e a criatividade para combater esse vírus.

Palavras chave: Coronavirus, Pandemias, Saúde pública.

\section{ABSTRACT}

Objective: To report the experience of implementing coordinated actions adopted in an Integrated Inclusion and Rehabilitation Center to prevent the new Coronavirus. Experience report: This study is an experience report of a descriptive nature of the implementation of coordinated actions for the prevention of the new coronavirus following the federal, state and municipal health recommendations. Among the actions implemented by the crisis committee, backup of assistance activities, clinical protocols, communication material, psychological monitoring for employees and testing. Final considerations: The center adopted all measures directed by Organs health agencies, implementing actions in an organized manner and multiplying information among employees, users and family members. It is important to implement a mass testing policy. Possibly we would have a more reliable epidemiological map for analysis, also placing on the agenda the socioeconomic discussions that are quite different in Brazil. The moment is to gather all the opinions and creativity to fight this virus.

Keywords: Coronavirus, Pandemics, Public health.

\section{RESUMEN}

Objetivo: Informar la experiencia de implementar acciones coordinadas adoptadas en un Centro Integrado de Inclusión y Rehabilitación para prevenir el nuevo Coronavirus. Informe de experiencia: Este estudio es un informe de experiencia de naturaleza descriptiva de la implementación de acciones coordinadas para la prevención del nuevo coronavirus siguiendo las recomendaciones de salud federales, estatales y municipales. Entre las acciones implementadas por el comité de crisis, respaldo de actividades de asistencia, protocolos clínicos, material de comunicación, monitoreo psicológico para empleados y pruebas. Consideraciones finales: El centro adoptó todas las medidas dirigidas por las agencias de salud, implementando acciones de manera organizada y multiplicando la información entre empleados, usuarios y familiares. Es importante implementar una política de pruebas masivas. Posiblemente tendríamos un mapa epidemiológico más

${ }^{1}$ Centro Integrado de Inclusão e Reabilitação (CIIR/INDSH), Belém - PA. *E-mail: qualidade.ciir@indsh.org.br SUBMETIDO EM: 6/2020 ACEITO EM: 7/2020

PUBLICADO EM: 9/2020 
confiable para el análisis, también colocando en la agenda las discusiones socioeconómicas que son bastante diferentes en Brasil. El momento es reunir todas las opiniones y la creatividad para combatir este virus.

Palabras clave: Coronavirus, Pandemias, Salud pública.

\section{INTRODUÇÃO}

Coronavírus é um vírus da classe de vírus envelopados de RNA positivo não segmentado com a característica do seu capsídeo circular com espículas de proteínas semelhante à corona solar e que são responsáveis por infecções respiratórios (QUINTILIO W e TROI M, 2020).

A Organização Mundial de Saúde (OMS) reconheceu em 11 de março a pandemia em relação à doença do novo coronavírus-2019 denominada COVID 19, que é doença respiratória causada pelo vírus Sars-Cov-2. Surgi então dúvidas de como enfrentar esse perigo com uma grande potencialidade de contaminação. Haja vista das dificuldades de implantação e cumprimento das medidas sanitárias para controlar essa doença (WERMUTH MAD e MORAIS JLB, 2020).

O impacto da evolução dos casos da Sars-Cov-2 é preocupante em relação a condições de infraestrutura médico hospitalar, associados as evoluções geométricas da doença que exige estratégias rápidas para maximizar e otimizar recursos públicos. Além dos desafios econômicos, onde emprego e renda são fundamentais na reprodução da vida das famílias (OMS, 2020).

Os sintomas são febres, cansaço e tosse seca. Outros pacientes podem ter dores, congestão nasal, corrimento nasal, dor de garganta ou diarreia. Alguns pacientes são infectados, mas não apresentam sintomas e não sentem mal. Cerca de $80 \%$ das pessoas se recuperam da doença sem precisar de tratamento.

Uma a cada seis pessoas fica gravemente doente e desenvolve dificuldade em respirar. Pessoas idosas, com pressão alta, problemas cardíacos ou diabetes, têm probabilidade de desenvolver doença grave (OPAS, 2020).

A demora em testar os suspeitos, dar os resultados e isolar, além dos contactantes não procuram os serviços de saúde quando desenvolvem doença leve, dificulta o controle da pandemia. São fatores que estão espalhando a doença no mundo. Ressaltar também as falhas na proteção dos profissionais de saúde, o que gera disseminação nos serviços de saúde (SILVA AAM, 2020).

A rápida difusão internacional do Coronavírus em casos e óbitos, trazem preocupações e ações para tornar essa pandemia global com menores impactos humanos e desaceleração econômica mundial. A cooperação cientifica e tecnológica em maior escala faz necessário urgentemente e um momento que não há apresentações de ações e surgimento de políticas econômicas nacionais ou flexibilização fiscais (SENHORAS EM, 2020).

Segundo a Sociedade Brasileira de Imunologia (2020), ainda é precoce a recomendação da hidroxicloroquina para tratamento da COVID 19. Alguns estudos mostram não haver benefícios para os pacientes e as considerações relacionadas aos efeitos adversos graves que esses medicamentos podem causar.

Para respostas de ponta, necessita de ações coordenadas e pesquisas cientificas voltadas para desenvolver tratamentos específicos. As publicações nesse momento têm muito a contribuir para reflexão da prática atual e compartilhamento com a sociedade acesso a informações. A rápida disseminação do vírus e potencial destruidor da economia e do sistema de saúde, exige um comportamento e atitudes colaborativas coletivas e individuais até que aguardamos uma resposta unificada (BARBOSA ACQ, 2020).

Todos devem seguir as orientações e recomendações sanitárias diante desse fato inédito imposto no país. Compartilhamento de informações errôneas podem trazer consequências devastadoras. A informação é uma ferramenta importante nesse momento de pandemia quando usado com responsabilidade social (JUNIOR JL, 2020). Diante desse cenário, esse estudo tem como objetivo relatar a experiência e as ações estratégicas em um Centro Integrado de Inclusão e Reabilitação para prevenção de contágio ao novo Coranavírus. 


\section{RELATO DE EXPERIÊNCIA}

Visto a relevância da temática procede com a descrição das ações coordenadas adotadas no momento para prevenção de contágio do vírus no Centro Integrado de Inclusão e Reabilitação.

\section{Implantação do Comitê de crise}

O comitê foi criado por pessoas preparadas para lidar com a pressão no momento, portanto foi composta pela diretoria executiva, diretoria técnica, gerência assistencial e administrativa financeira, além da representante do serviço de controle de infecção hospitalar e representante do núcleo da qualidade e segurança do paciente.

As reuniões acontecem diariamente para entendimento da evolução da pandemia local, levantamento das informações relevantes, definição do canal oficial de comunicação, definições de multiplicadores das informações na instituição e mantimento da rotina de trabalho.

Com a velocidade de informações, ocorreu a necessidade de tomar decisões rapidamente para garantir a segurança dos colaboradores e usuários. Orientação a todos os colaboradores sobre a colocação, guarda e retirada de máscara, paramentação e desparamentação desinfecção de superfície.

O comitê apresenta soluções com agilidade ao responder e implantar ações estratégicas rapidamente, haja vista que as recomendações da Organização Mundial de Saúde, Ministério da Saúde e Secretária de Estado da Saúde do Pará lançam boletim diários de recomendações nas quais adotamos como referência.

\section{Backup de atividades essenciais}

Desenvolvido um plano de ação para transição de atividades essenciais, visando decidir quais áreas estratégicas serão consideradas e que deverão ser mantidas. Garantir a continuidade das atividades, assegurando a sustentabilidade da empresa e seus colaboradores caso haja afastamentos de casos suspeitos ou confirmados.

\section{Implantação do protocolo clínico de manejo de casos suspeitos de Coronavírus}

Foi criado e posteriormente multiplicado para a equipe, um protocolo de manejo de casos suspeitos de Coronavírus, onde todos os envolvidos direto e indiretamente na assistência ao usuário. Os critérios de inclusão são para os usuários ou colaboradores que estiverem incluídos nos casos suspeitos (todos os indivíduos que apresentam sinais e sintomas respiratórios e pessoas que residam no mesmo endereço mesmo assintomático, devem permanecer em isolamento domiciliar/social por 14 dias).

No centro, o fluxo de atendimento aos sintomáticos respiratórios foram realizados através da triagem na entrada para todos. Usuários, colaboradores e acompanhantes foram abordados e questionados sobre a presença de sintomas gripais e febre. Caso a presença de sintomas gripais, o mesmo receberá uma máscara para proteção, assim como seu acompanhante, se couber. Após primeira triagem, todos os usuários e acompanhantes passarão por triagem de enfermagem com aferição de temperatura e saturação de oxigênio. Caso positivo os sinais e sintomas, o mesmo será encaminhado para o clínico geral para avaliação e afastamento social para isolamento domiciliar.

Os residentes do domicílio do suspeito, assinarão termo de consentimento livre e esclarecido para isolamento de sintomático. Caso suspeito se enquadra em sintomas mais graves será acionado o time de resposta rápida com código $\mathrm{C}$ e conduzido para sala de isolamento. Logo após contra referenciado para hospitais de referência da cidade.

\section{Implantação do protocolo para recomendação de atendimento odontológico durante a pandemia COVID-19 no Centro de Especialidades Odontológicas II.}

Os procedimentos odontológicos foram realizados somente em casos de emergência que potencializam o risco de morte do paciente, situações de sangramentos não controlados, celulites ou infecções bacterianas difusas e traumatismo de face que comprometa vias aéreas do paciente. Todos os procedimentos devem seguir as recomendações a fim de reduzir o risco de contaminação no ambiente de trabalho e o próprio procedimento. 


\section{Implantação de materiais de comunicação}

Foram criados e multiplicados materiais de comunicação com orientações de prevenção, isolamento sintomático, domiciliar ou hospitalar dos casos suspeitos por até 14 dias, triagem em serviços de saúde com recomendações que os pacientes com forma leve da doença não procurem atendimento nas UPAs e serviços terciários e utiliza a infraestrutura de suporte disponibilizada pela atenção primário de saúde e estratégia da família, equipamento de proteção individual com recomendações de uso de EPI para doentes, contatos domiciliares e profissionais de saúde e recomendações de contato próximo.

\section{Usuários do programa de reabilitação}

O vídeo é um meio de comunicação e de ensino na ausência das terapias nesse momento. A produção foi feita pela as especialidades (fisioterapia, fonoaudiologia, terapia ocupacional, enfermagem, psicologia, musicoterapia, nutrição). Após a criação, o mesmo foi avaliado o conteúdo científico para avaliação de exatidão, atualização, clareza, contextualização, adequação da linguagem/conteúdo para o público alvo e as referências. Em seguida, disponibilizado para os usuários através de aplicativo de mensagem instantânea.

Os serviços de reabilitação, por meio da sua equipe multiprofissional, têm autonomia para continuar o acompanhamento dos usuários, conforme avaliação clínica individual; os usuários que estiverem no programa de estimulação precoce não devem ser encaminhados aos serviços de atenção primária em saúde. Os serviços de reabilitação foram identificados o público de risco e orientá-los ao isolamento, conforme recomendações do Ministério da Saúde.

Os serviços de reabilitação deverão estabelecer protocolos ou restrições para acesso aos pacientes, evitando aglomerações e minimizando o risco de transmissão ou contágio. Os serviços de reabilitação também ofereceram retaguarda para atendimento aos usuários pós internações originadas pela COVID-19 que gerem déficits de funcionalidade. Os serviços de reabilitação informaram uma lista nominal às Secretarias de Saúde do Estado do Pará os pacientes em atendimentos, os classificados no grupo de riscos e aqueles identificados como casos suspeitos. Todos os profissionais utilizam os equipamentos de proteção individual. Todos os casos suspeitos foram notificados a vigilância epidemiológica e a equipe se manteve a disposição para atendimentos de casos do COVID-19 (MS, 2020).

\section{Acompanhamento dos colaboradores pelo serviço social e psicologia}

Em uma pandemia, o medo aumenta os níveis de ansiedade e estresse em indivíduos saudáveis e intensifica os sintomas daqueles com transtornos psiquiátricos pré-existentes. Nesse período foi disponibilizado os serviços sociais e psicológicos conforme a demanda e as necessidades identificadas e disponibilidade de EPI's aos mesmos.

\section{Fabricação de protetores faciais para os profissionais de saúde e câmeras de oxigênio}

Confecções de protetores faciais foram distribuídos aos profissionais de saúde que atuam na linha de frente de combate ao vírus no estado. Os protetores faciais são feitos de polipropileno, acetato e foram confeccionados na oficina de produção de órtese e prótese. Cerca de 20 profissionais foram envolvidos no processo de produção e entrega, chegando um total de produção de 2.500 protetores faciais e 143 câmeras de oxigenioterapia disponibilizados para Secretária de Estado de Saúde Pública do estado do Pará.

\section{Realização de testes PCR e teste rápido para diagnósticos para COVID-19}

A coleta de amostra respiratória foi realizada até o $3^{\circ}$ dia e eventualmente, poderá ser feita até $07^{\circ}$ dia, após o início dos sintomas. Para os indivíduos que atenderam a definição de caso suspeito está indicada a coleta de uma amostra, a qual pode ser feita pelas técnicas de aspirado de nasofaringe (ANF) ou swab combinado (nasal/oral) e colocada em meio de transporte Hanks, seguindo o protocolo de Influenza.

A amostra deverá ser encaminhada refrigerada $\left(4-8^{\circ} \mathrm{C}\right)$ em caixa de transporte de amostras biológicas ao LACEN/PA imediatamente (em até no máximo 24h), juntamente com o relatório do GAL, ficha de notificação do SINAN (notificação/conclusão), ficha do FormSUS2 e nova ficha de SRAG (casos que também se enquadrem na definição de caso de SRAG), para serem processadas. 
O LACEN/PA divide a amostra em duas alíquotas e encaminha uma alíquota para o Instituto Evandro Chagas (IEC). A requisição deverá ser cadastrada no Sistema de Gerenciador de Ambiente Laboratorial (GAL), deve-se selecionar a opção "Novo Coronavírus-COVID-19" (LACEN, 2020).

A notificação dos casos suspeitos de COVID-19 não hospitalizados deve ser feita por meio do preenchimento da ficha de notificação/conclusão do SINAN e da notificação on-line da ficha do e-SUS VE (desde o dia 27/03/2020), com letras maiúsculas e sem acento. O registro no e-SUS VE deve ser realizado pelas VE municipais ou serviços de saúde por meio do link https://notifica.saude.gov.br (DATASUS, 2020).

É recomendado que o profissional que realizará o procedimento de coleta de amostra esteja devidamente paramentado com equipamento de proteção individual (EPI) adequado, o que inclui gorro descartável, luva de procedimento, avental de mangas compridas, óculos de proteção e uso de máscara N95, PFF2 ou equivalente. Os estabelecimentos de saúde privados deverão notificar todos os casos suspeitos para COVID19 que se enquadrem na definição de caso.

O caso que foi atendido na rede privada deve ser notificado na ficha do FormSUS2, ficha de notificação do SINAN (notificação/conclusão) e nova ficha de SRAG Hospitalizado, e caso o resultado seja positivo, comunicar imediatamente a vigilância epidemiológica municipal, e esta, ao DEPI e CIEVS. As amostras coletadas nos serviços de saúde privados deverão ser analisadas pelos laboratórios privados credenciados (Sabin, DASA e Hermes Pardini) e com exames validados. Apesar de ter sido anunciado em coletiva de imprensa pelo Ministro da Saúde, até o momento não há nenhuma diretriz ou recomendação quanto ao uso e distribuição de testes rápidos para diagnóstico/triagem de COVID-19, ou seja, a SESPA não recebeu nenhuma diretriz sobre quais os testes indicados, quem será testado ou em que situações (LACEN, 2020).

Importante ressaltar o distanciamento social através do isolamento de todas as recepções, descentralização das recepções, além de bloqueio de assento, mantendo o distanciamento de 1,5 metros. Os pacientes que alguns sintomas característicos, o exame, terapia ou a consulta foram remarcados. Restrição de 1 acompanhamento foram determinadas para evitar aglomeração.

\section{DISCUSSÃO}

Os países enfrentam cada vez mais a transferência de riscos e oportunidades para saúde. O grande fato importante que o mundo não está preparado para lidar com emergências de saúde pública e pessoas correriam risco de morte caso corresse uma pandemia de grandes proporções (OLIVEIRA TQ, et al., 2014).

Conforme MS (2020), o adoecimento de profissionais de saúde reduz o recurso humano que pode comprometer a qualidade e resposta para os serviços dos serviços de saúde. Todos os colaboradores que executam atividades de contato direto e indireto com pacientes, utensílios, objetos e ambientes possivelmente infectados. Os trabalhadores precisam ser informados, treinados, conscientizados e mobilizados para ações de proteção necessária.

O Comitê de crise teve um papel fundamental para criar estratégias e implantar os multiplicadores na instituição para disseminar as informações de forma padronizada, tornando o ambiente seguro de trabalho, com medidas preventivas compatíveis com suas atividades de rotina e as decorrentes de atendimento ao COVID 19. Todos os colaboradores foram treinados sobre uso correto de EPIs e utilização em cada situação, sua colocação, sinais de dano ou avaria, retirada e descarte adequado e seguro, identificados os colaboradores que se enquadram no grupo de risco.

Os Treinamentos foram assessorando pelo Núcleo de educação permanente. Além de orientações gerais sobre evitar abraços, beijos, apertos de mão e distanciamento de 1 metro entre os colaboradores e os pacientes com colação inclusive de barreias nas recepções. Entendemos que a informação é a melhor ferramenta para segurança dos colaboradores, usuários e no próprio domicílio.

Importante ressaltar, que ocorreu monitoramento de ocorrência de transmissão interna e externa entre os colaboradores. Os colaboradores que positivaram para COVID 19, foi adotado medidas apropriadas para controle e mitigação da transmissão, além de acompanhamento interdisciplinar desses colaboradores em todo momento de tratamento, garantindo conforto físico e mental para os mesmos. 
A Organização Mundial de Saúde recomenda a introdução de mudanças de hábitos e comportamento, controle à exposição de situações nocivas à saúde e reformas das leis referentes à saúde pública (OMS 2011).

As epidemias fazem parte da realidade mundial, um mundo cada vez mais globalizado, porém sensível e vulnerável a agentes biológicos. A cooperação internacional, transparência comunicacional e respostas compartilhadas nesse momento torna-se essencial para saúde pública e reduzindo consequências econômicas e os riscos epidemiológicos (SENHORAS EM, 2020).

Importante que as ações sejam realizadas com qualidade e os serviços prestados diminuem a probabilidades de resultados desfavoráveis e aumentam os resultados favoráveis. A segurança de todos deve ser considerada o mínimo aceitável de risco de dano desnecessário associado ao cuidado de saúde. Necessário o trabalho integrado e que os esforços sejam concentrados para correções dos processos inseguros (MILAGRES LM, 2015).

\section{REFERÊNCIAS}

1. ARRAIS TS, OLIVEIRA AR. Pandemia COVID-19: O caráter emergencial das transferências de renda direta e indireta para a população vulneráveis do estado de Goiás. Universidade Federal de Goiás. Programa de Pós-Graduação em Geografia. Observatório do Estado Social Brasileiro.

2. BARBOSA ACQ. Lições sobre a pandemia da COVID-19 e a informação cientifica. Revista da rede de atenção primária à saúde, 2020;2(1):70-72.

3. DATASUS. Ministério da saúde. Secretária de vigilância em saúde Datasus.saude.gov.br.2020.

4. JÚNIOR JL. As implicações criminais das "fake News" entre outras condutas, diante da pandemia do novo Coronavírus (COVID-19). Revista prática Forense,2020;39.

5. LACEN. Laboratório central. Diretoria de vigilância à saúde. Secretaria de saúde do Pará. Guia de coleta.2020.

6. MALIK AM, et al. Segurança do paciente na cultura organizacional: percepção das lideranças de instituições hospitalares de diferentes naturezas administrativas. Revista da Escola Enfermagem da USP, 2016:50(3);490-497.

7. MS. Secretaria de Atenção Especializada à Saúde Departamento de Atenção Hospitalar, Domiciliar e de Urgência. Protocolo de Manejo clínico da COVID-19 na atenção especializada.2020.

8. MALIK AM, et al. Segurança do paciente na cultura organizacional: percepção das lideranças de instituições hospitalares de diferentes naturezas administrativas. Revista da Escola Enfermagem da USP, 2016:50(3);490-497.

9. MORAIS JLB, WERMUTH MAD. Da exceção Agambeniana à construção planetária de ferrajoli: desafios impostos pela pandemia do novo Coronavírus às categorias jurídico-políticas tradicionais. Revista eletrônica do curso de direito da UFSM, 2020;15(1):1-29.

10. MILAGRES LM. Gestão de riscos para segurança do paciente: o enfermeiro e a notificação dos eventos adversos. Juiz de Fora. Dissertação (Mestrado em enfermagem) - Faculdade de Enfermagem da Universidade Federal de Juiz de Fora, Minas Gerais, 2015, 99 p.

11. ORGANIZAÇÃO MUNDIAL DA SAÚDE (OMS) BRASIL.2020.In:Publicações da OMS: https://www.who.int/eportuguese/publications/pt/.Acesso em: 20 abr.2020.

12. ORGANIZAÇÃO PAN-AMERICANA DA SAÚDE (OPAS) BRASIL.2020. In: Covid-19. Doença causada pelo Coronavírus. Disponível: htpp:// em https://www.paho.org/bra/. Acesso em: 20 abr.2020.

13. ORGANIZAÇÃO MUNDIAL DA SAÚDE (OMS). 2011. In: Relatório Mundial da saúde. Financiamento dos sistemas de saúde. O caminho para a cobertura universal. Disponível: apps.who.int/iris/bitstream/handle. Acesso em: 20 abr.2020.

14. OLIVEIRA TQ, et al. Pandemias em um mundo globalizado: desafios para o acesso universal à saúde. Simulação das Nações Unidas para secundaristas.2014.

15. QUINTILIO W, TROI M. Coronavírus: lições anti-negacionistas e o futuro do planeta. Scielo em perspectiva, 2020;1145.

16. SENHORAS EM. Novo Coranavírus e seus impactos econômicos no mundo. Revista UFRR, 2020;1(2):39-42.

17. SOCIEDADE BRASILEIRA DE IMUNOLOGIA. Parecer sobre utilização da cloroquina-hidroxicloroquina para tratamento da Covid 19.2020.

18. SILVA AAM. Sobre a possibilidade de interrupção da epidemia pelo Coronavírus (COVID-19) COM base nas melhores evidências científicas disponíveis. Revista Brasileira de Epidemiologia, 2020;23.

19. Vidale Giulia. Hidroxicloroquina em pacientes leves pode prevenir internação, diz estudo. [Publicação na web]; 2020. 